\title{
INTEGRATING SURFACE AND BOREHOLE GEOPHYSICS IN THE CHARACTERIZATION OF SALINITY IN A COASTAL AQUIFER
}

\author{
F.L. Paillet \\ U.S. Geological Survey, USA
}

\begin{abstract}
A combination of geologic descriptions of cores, borehole geophysics, surfacegeophysical soundings and water-sample analyses was used to characterize flow in the surficial aquifer in the vicinity of Big Cypress National Preserve, Collier County, south Florida. The geophysical analysis augmented by aquifer tests and piezometer measurements showed that the surficial aquifer is under unconfined conditions, is in hydraulic connection with surface water bodies, and is underlain by a series of confining units and confined aquifers. Sea-water intrusion appears as a simple wedge of saline water underneath the coastal region. The pattern of salinity in the underlying aquifers is variable and shows no relation to distance from the coast or from the surficial wedge of sea-water intrusion. Borehole flow-log data document the existence of a strong vertical hydraulic-head gradient throughout the study area. The subsurface distribution of salinity in the study area apparently is determined by variations in the amount of seepage of saline water from underlying aquifers and not by lateral sea-water intrusion except near the wedge of sea water imaged by the surface geophysics.
\end{abstract}

\section{INTRODUCTION}

Unless subsurface conditions are unusually homogenous, coastal aquifers cannot be adequately characterized by just drilling and logging in a limited number of boreholes. Non-invasive surface geophysical measurements can provide the area-wide coverage needed for such characterization. Surface electromagnetic soundings can be especially effective in identifying intrusion of salt water because the presence of saline water in aquifers produces a measurable decrease in the electrical resistivity of subsurface formations. However, there are two significant drawbacks in using surface geophysics to investigate sea-water intrusion in coastal aquifers: 1) the interpretation of surface geophysical measurements may be ambiguous; and 2) some hydrologic conditions related to ground-water flow may not be indicated by aquifer geometry as imaged from the surface. The ambiguity arises from such sources as limited spatial resolution associated with depth of penetration; the complex relationship between subsurface electrical conductivity and the combination of porosity, pore-water salinity, and clay mineral fraction; and the equivalence of different interpretation models in data inversion [electrical non-uniqueness; Sharma, 1997]. At the same time, hydraulic conditions such as head gradients and flow-path boundary conditions can influence the distribution of 
ground-water salinity independent of aquifer geometry as given by the interpreted geophysical data.

Integration of surface geophysical soundings and geophysical logs from a few boreholes can be used to remove the ambiguity from the geophysical interpretation by showing the exact depth limits of aquifer geometry and to identify the nature of hydraulic conditions that influence sub-surface flow. The significance of integrating surface and borehole geophysics in the characterization of coastal aquifers is illustrated with a case study from south Florida. In this study, drillers and geophysical logs from a few boreholes are used to construct a model for aquifer geometry that can be extrapolated over the regions between boreholes using time-domain electromagnetic (TEM) soundings [Kaufman and Keller, 1983]. Hydraulic conditions within and adjacent to the boreholes are inferred from borehole flow logs and aquifer tests and are used to determine the boundary conditions influencing flow within the aquifers identified by the geophysical analysis. This integrated analysis of surface and borehole geophysics results in a coherent interpretation of subsurface conditions that could not have been achieved by using either surface or borehole methods alone.

\section{GEOPHYSICAL LOGS}

The study described in this report was undertaken to determine the effects of manmade structures such as roads and canals on the subsurface intrusion of sea water in the vicinity of Big Cypress National Preserve, Collier County, south Florida [Weedman et al., 1997, 1999]. The first steps in the investigation were the identification of existing borehole data, and the drilling and logging of boreholes in those parts of the study site where such data did not exist [Paillet and Reese, 2000; Fig. 1]. Lithology from core descriptions and drillers logs indicated that there were no clay minerals in the formations encountered by the boreholes and that all sediments were a mixture of unconsolidated carbonate and silica grains. Although a full suite of geophysical logs were obtained from the first two boreholes, analysis of log data and core samples showed that a combination of electrical-induction and neutron-porosity logs (Fig. 2) were sufficient to identify aquifer structure. Comparison of the neutron-porosity log with the induction log allowed effective separation of the effects of salinity from the effects of clay mineral fraction and formation permeability on the measured electrical conductivity of the formation [Paillet et al., 1999]. The analysis showed that the surficial sediments consist of an unconfined aquifer separated from additional underlying aquifers by one or more confining units. Abrupt changes in formation electrical conductivity on the induction log coincide with depths where confining units separate aquifers containing water of different salinity. Core samples indicated that confining units were those layers where carbonate cement had reduced the permeability of sediments [Weedman et al., 1997]. Regression of the electrical conductivity of water samples against the electrical conductivity of aquifers indicated an effective formation factor of about 2.3 [Paillet et al., 1999], which could be used to predict the salinity of the subsurface on the basis of electromagnetic measurements. 


\section{ELECTROMAGNETIC SOUNDINGS NEXT TO BOREHOLES}

Although the geophysical logs gave a useful interpretation of subsurface aquifer conditions, those results only applied to the immediate vicinity of boreholes, which are separated by 10 or more kilometers. Surface TEM soundings were made in the vicinity of five boreholes (Fig. 3) to identify the correspondence between local aquifer geometry given by the induction log and the layers given by typical TEM interpretation techniques [Fitterman and Stewart, 1986]. This method involves the minimization of the difference between the TEM sounding data and predictions based on a subsurface model containing a specified number of layers of given thickness and resistivity. Induction logs provided the information needed to select the single TEM inversion model among a set of essentially equivalent models that gave the best representation of the subsurface structure. On the basis of this comparison, the TEM soundings obtained adjacent to boreholes appear to indicate three parameters: 1) electrical conductivity of the uppermost aquifer, 2) the depth to the bottom of the uppermost aquifer, and 3) average electrical conductivity of the underlying aquifers and confining units down to an approximately $75 \mathrm{~m}$ depth of investigation.

\section{SURFACE ELECTROMAGNETIC SOUNDING PROFILES}

Several lines of TEM soundings were made at approximately $0.5 \mathrm{~km}$ intervals along profiles connecting several of the boreholes. Fig. 4 illustrates typical results from the analysis of these profiles. Comparison of profiles generated using two- and threelayer interpretation models demonstrates that there is no significant improvement to the interpretation with the addition of the third layer, as inferred from the comparison with logs in Fig. 3. The 2-layer profile in Fig. 4 is interpreted to represent the electrical conductivity of the uppermost aquifer, and the average electrical conductivity of the underlying combination of confining units and aquifers down to an approximately $75 \mathrm{~m}$ depth of investigation. The interpretation shows a wedge of sea-water intrusion on the south side of the uppermost aquifer. The shape and slope of the sea-water/fresh-water contact shown on the left hand side of Fig. 4 was verified by obtaining a second set of TEM soundings at $100 \mathrm{~m}$ spacings, as shown on the figure. The nearly uniform electrical conductivity of the uppermost aquifer is consistent with the fact that this aquifer is connected to surface-water bodies having similar electrical properties. The electrical conductivity of the water in the upper aquifer, as determined from water samples and the application of the formation factor to induction log data, is comparable to the electrical conductivity of water in canals and ponds, which is about $400 \mu \mathrm{S} / \mathrm{cm}$. The underlying model layer in Fig. 4 shows variable electrical conductivity attributed to variations in the lithology, permeability, and water quality of the underlying formations. The model interpretations were subsequently verified by logging the rotary drilled verification boreholes indicated in Fig. 4 [Paillet et al., 1999]. Except for the wedge of sea-water intrusion, the interpretation indicates no correlation between pore-water electrical conductivity and distance from the coast. 


\section{HYDRAULIC CONDITIONS AT THE STUDY SITE}

Hydraulic conditions at the borehole sites were investigated by obtaining flow logs in fully screened boreholes under ambient and pumped or injection conditions, and by the measurement of water levels in piezometers completed in individual aquifer units [Paillet and Reese, 2000]. In almost all cases, the flow logs indicated a significant upward hydraulic-head gradient throughout the study site. Fully screened boreholes open between the surface and $50 \mathrm{~m}$ in depth had ambient upward flow of as much as $10 \mathrm{l} / \mathrm{min}$ driven by this gradient (Fig. 5). Piezometers completed in various depth intervals indicated $0.5 \mathrm{~m}$ or more hydraulic-head difference (corrected for salinity where necessary) between the shallow subsurface and permeable beds below $50 \mathrm{~m}$ in depth. Hydraulic tests further indicated that the uppermost aquifer was much more permeable than underlying aquifers and unconfined throughout the study area. These results, when combined with the TEM sounding interpretations in Fig. 4, indicate that the variations in the salinity of the shallow subsurface in the study area are attributed to variations in the rate of upward seepage. Although no geochemical analysis of water obtained in the study boreholes have been completed to date, the salinity of water in underlying aquifers is assumed to originate from carbonate brines known to saturate petroleum-bearing rocks in the study areas [Weedman et al., 1997]. The only place where sea water appears to affect the subsurface salinity is through the wedge of sea-water intrusion at the southern edge of the study area.

\section{CONCLUSIONS}

The local hydraulic properties of a coastal aquifer can be determined in a series of boreholes, but the large-scale geometry of heterogeneous aquifers is almost impossible to determine from a limited number of such data points. Non-invasive surface geophysical measurements can be used to map the regional-scale properties of the subsurface, but surface geophysical methods alone rarely provide the resolution to unambiguously characterize subsurface hydraulic properties. A combination of geological descriptions of cores, borehole geophysics, surface-electromagnetic soundings, water-sample analyses, and aquifer tests was used to successfully characterize flow in the surficial aquifer in the vicinity of Big Cypress National Preserve, Collier County, south Florida. The surficial aquifer is under unconfined conditions, is in hydraulic connection with surface water bodies, and is underlain by a series of confining units and confined aquifers. Sea-water intrusion appears as a simple wedge of saline water underneath the coastal region. The pattern of salinity in the underlying aquifers is variable and shows no relation to distance from the coast or the surficial wedge of sea-water intrusion. The borehole flowmeter profiles and piezometer data document the existence of a strong upward hydraulic-head gradient throughout the study area. The subsurface distribution of salinity in the study area is apparently determined by the amount of seepage of saline water from underlying aquifers and not by lateral sea-water intrusion everywhere except in the immediate vicinity of the wedge of sea water delineated by the surface geophysics. 


\section{References}

Fitterman, D.V. and Stewart, M.T., "Transient electromagnetic sounding for groundwater," Geophysics, 51(4), 995-1005, 1986.

Kaufman, A.A. and Keller, G.V., Frequency and transient soundings: Elsevier Science Publishers, Amsterdam, 1983.

Paillet, F.L., Hite, L. and Carlson, M., "Integrating surface and borehole geophysics in ground water studies - an example using electromagnetic soundings in south Florida," J. of Environmental and Engineering Geophysics, 4(1), 45-55, 1999.

Paillet, F.L. and Reese, R.S., "Integrating borehole logs and aquifer tests in aquifer characterization," Ground Water, 38(5), 713-725, 2000.

Sharma, P. V., Environmental and Engineering Geophysics, Cambridge University Press, Cambridge, UK, 1997.

Weedman, S.D., Paillet, F.L., Means, G.H. and Scott, T.M., Lithology and geophysics of the surficial aquifer system in western Collier County, Florida, U.S. Geological Survey Open-File Report 97-436, 1997.

Weedman, S.D., Paillet, F.L., Edwards, L.E., Simmons, K.R., Scott, T.M., Wardlaw, B.R., Reese, R.S. and Blair, J.L., Lithostratigraphy, geophysics, biostratigraphy, and strontium-isotope stratigraphy of the surficial aquifer system of eastern Collier County and northern Monroe County, Florida, U.S. Geological Survey Open-File Report 99-432, 1999.

Keywords: Borehole geophysics, induction logs, electromagnetic sounding, sea-water intrusion

Corresponding author: Frederick L. Paillet, U.S. Geological Survey, PO Box 25046, MS 403, Denver, CO 80225, USA.

Email: fpaillet@usgs.gov 


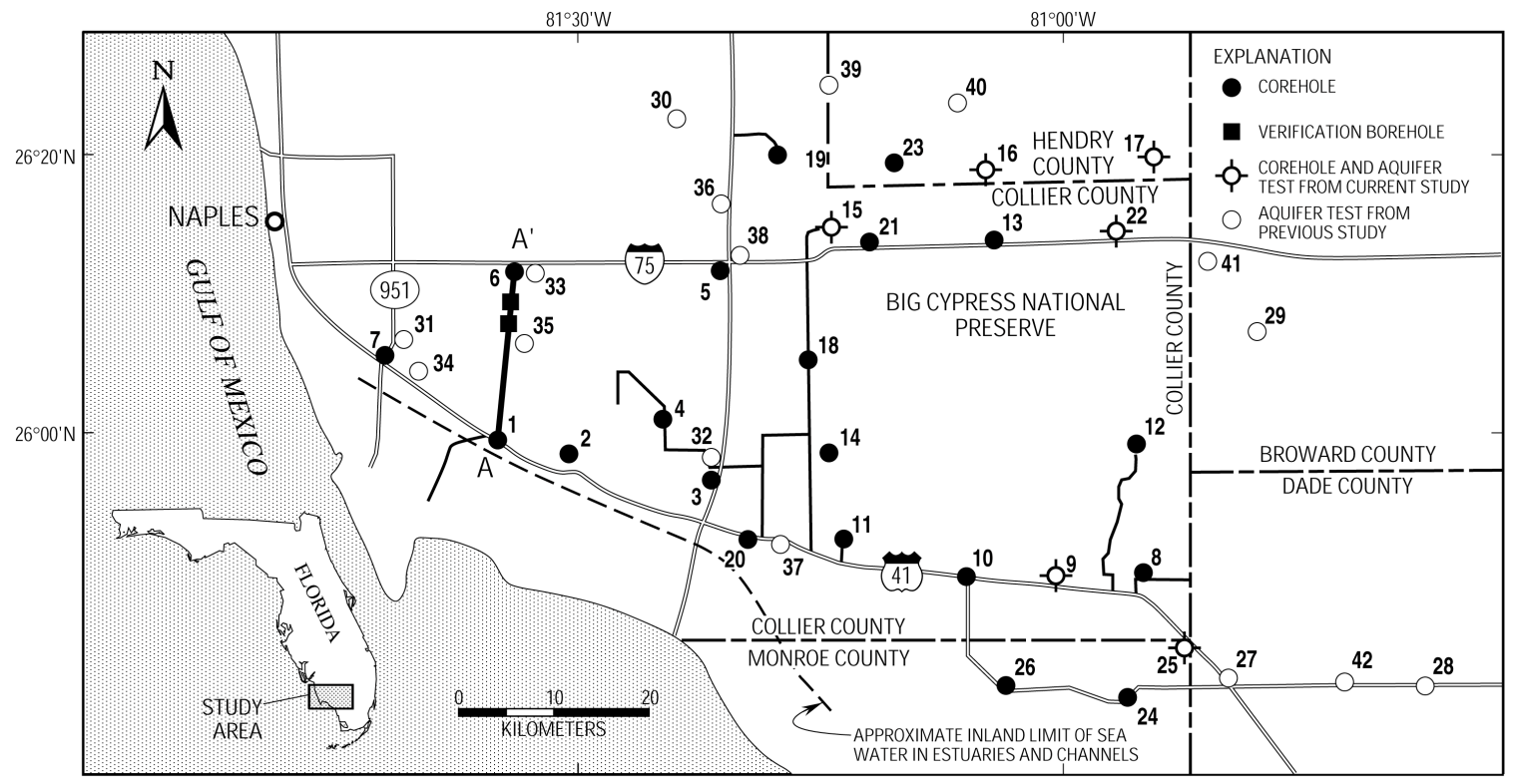

Figure 1: Location of boreholes drilled as part of this study, or where aquifer test data were obtained from previous studies. 


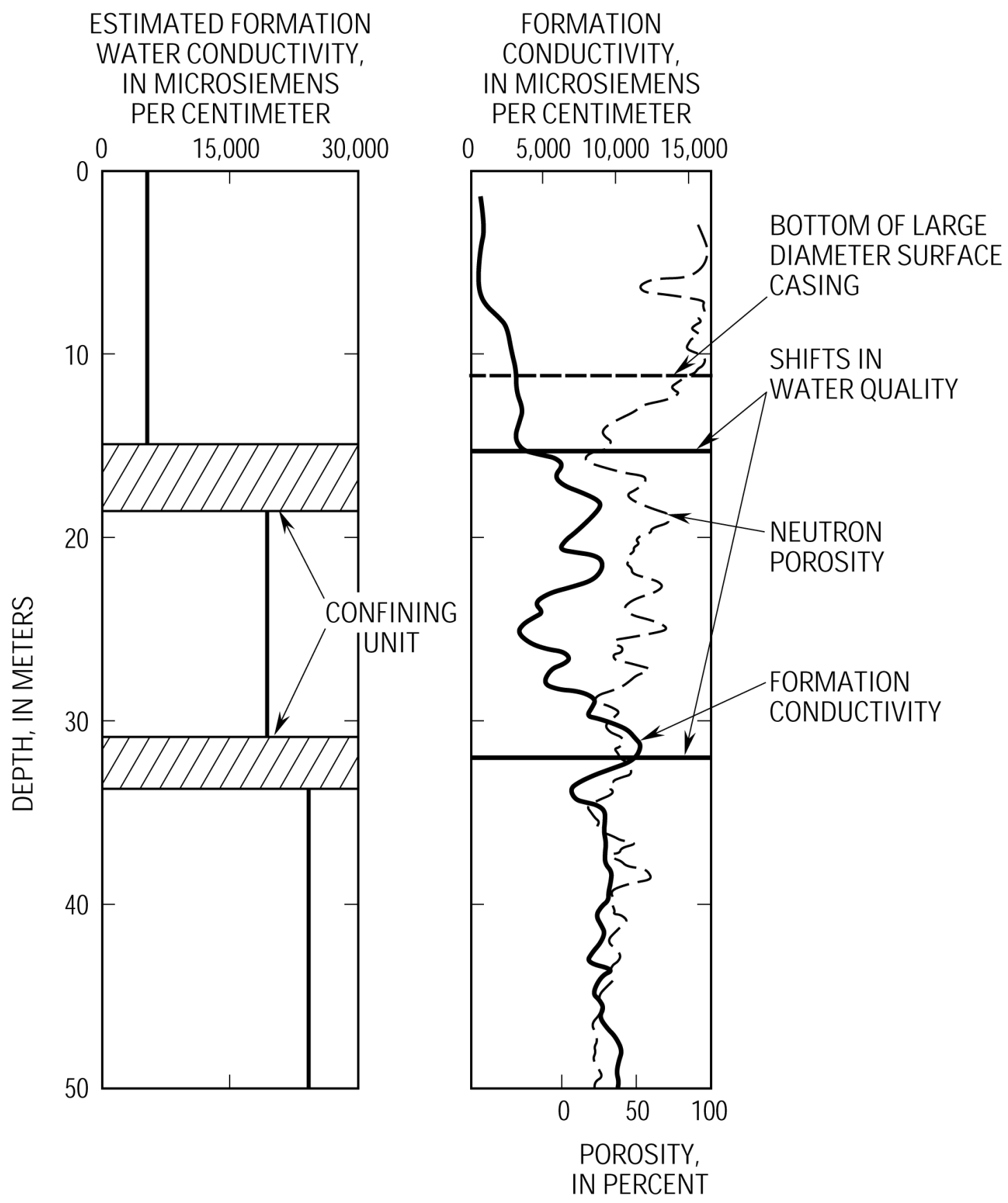

Figure 2: Comparison of induction and neutron porosity logs for borehole 2, showing step-like offsets in the induction logs that are interpreted as abrupt changes in water salinity where thin confining units separate aquifers in the shallow subsurface; note that unrealistically large porosity values above $10 \mathrm{~m}$ in depth are caused by a combination of large annulus and large diameter external surface casing. 


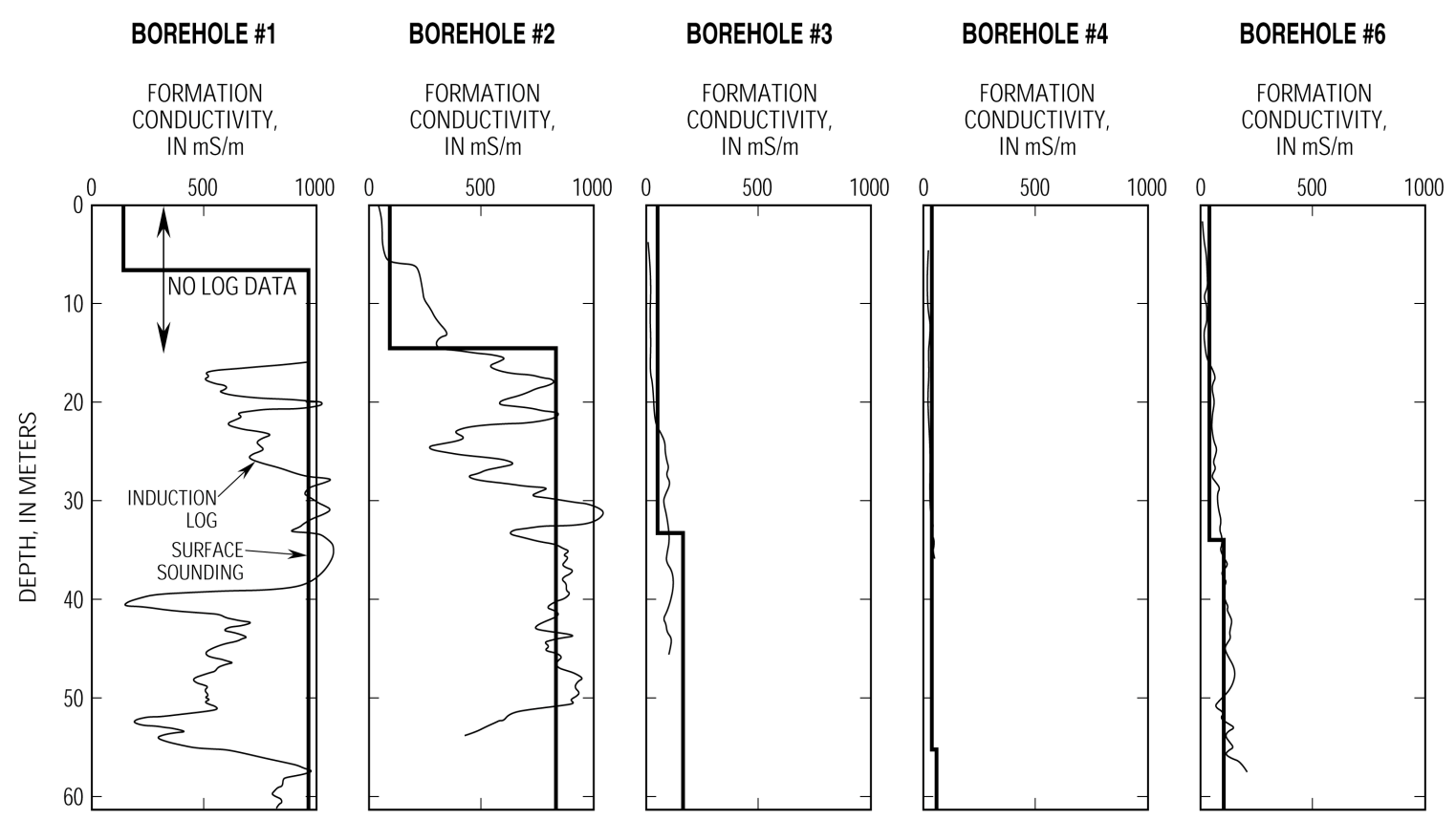

Figure 3: Comparison of induction logs with two-layer interpretations of TEM soundings adjacent to five of the first six boreholes; data not shown for borehole 5 because TEM soundings were invalidated by buried metal debris at that site. 


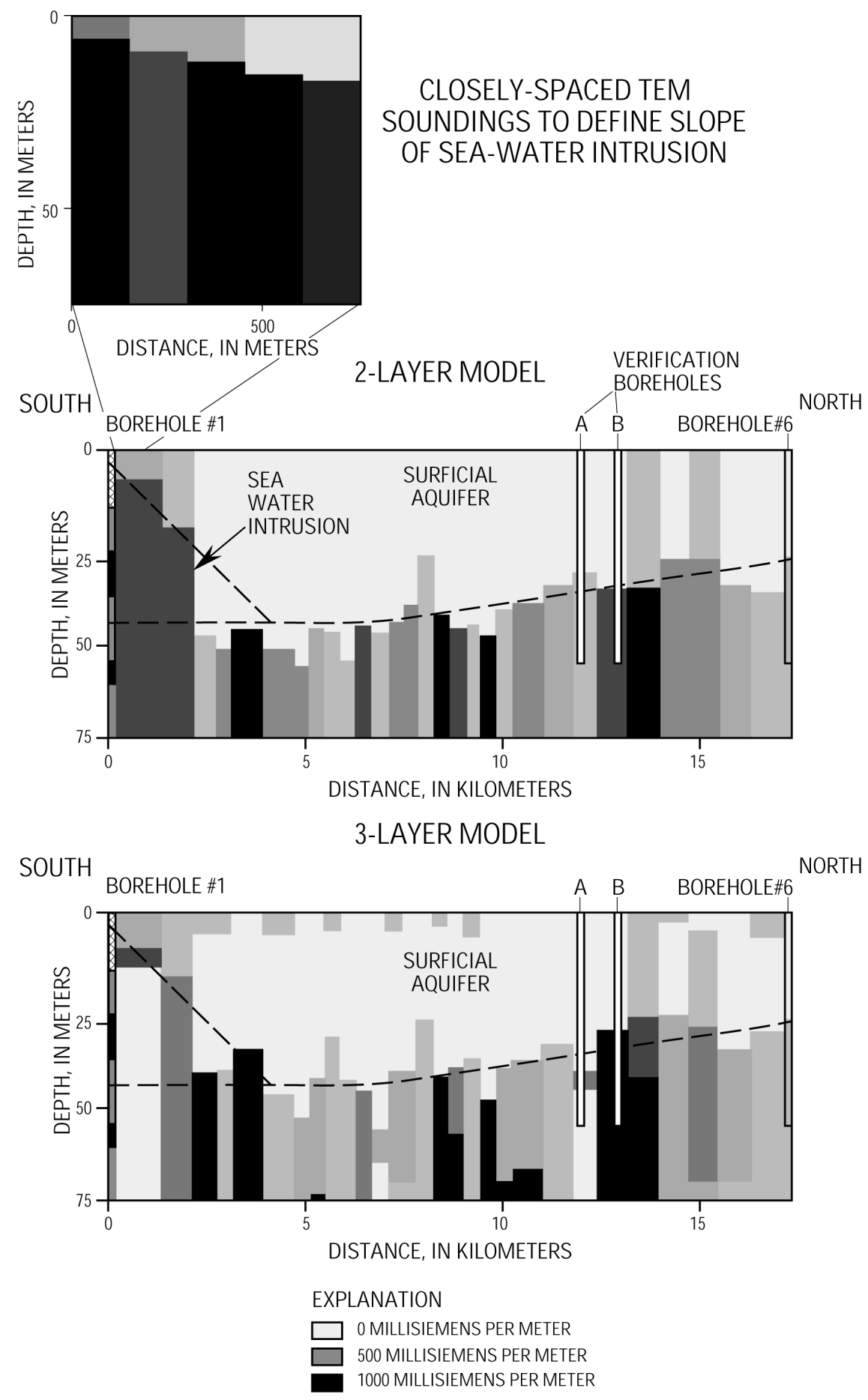

Figure 4: Composites of TEM soundings obtained along profile A in Fig. 1; two- and three-layer models are shown for comparison, and the locations are given for two verification boreholes subsequently drilled to check model predictions. Note that a detailed comparison of induction logs and TEM soundings for boreholes 1 and 6 are given in Fig. 3. 


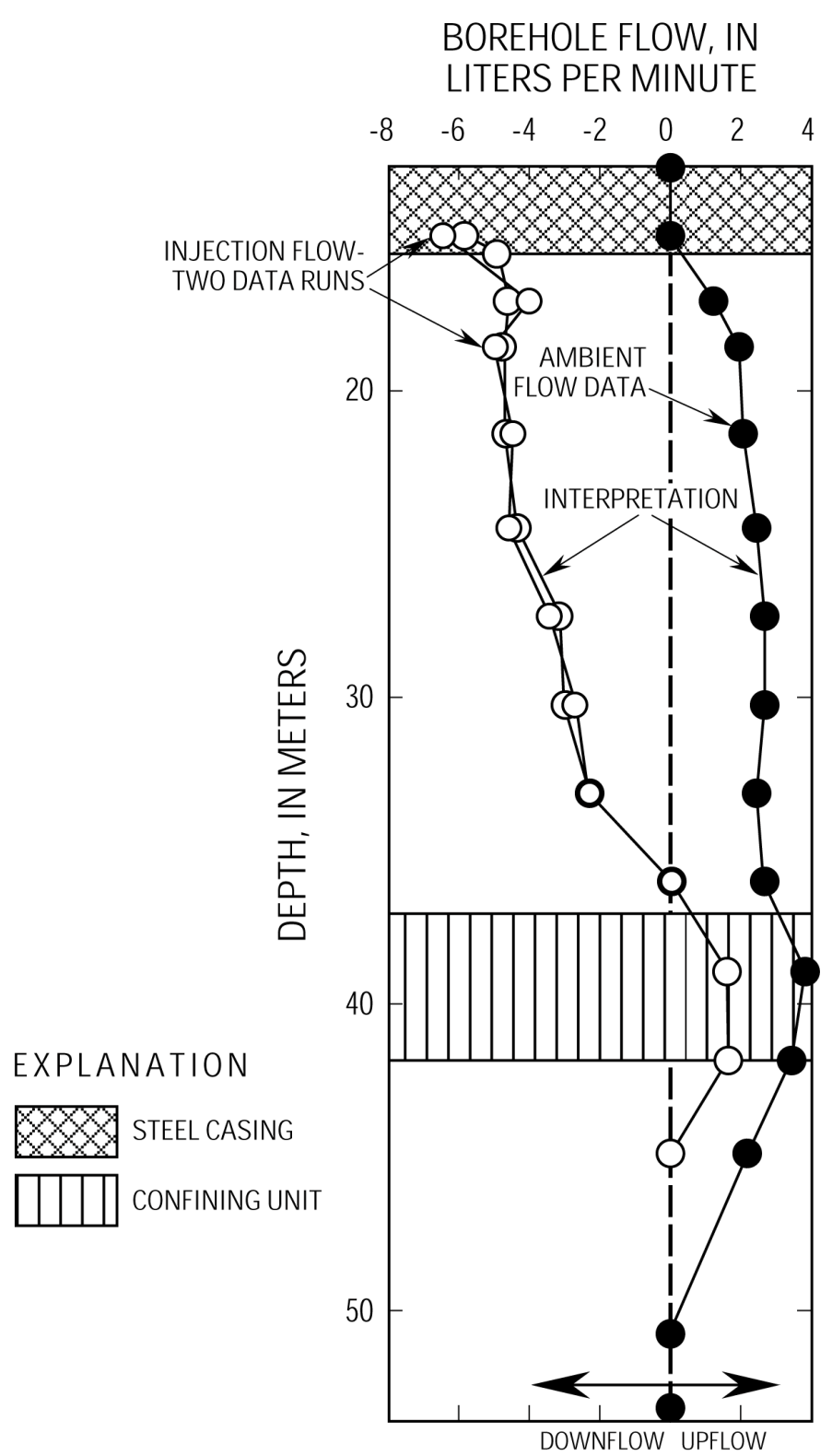

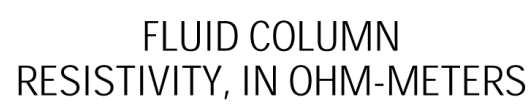

$\begin{array}{llll}0 & 1 & 2 & 3\end{array}$

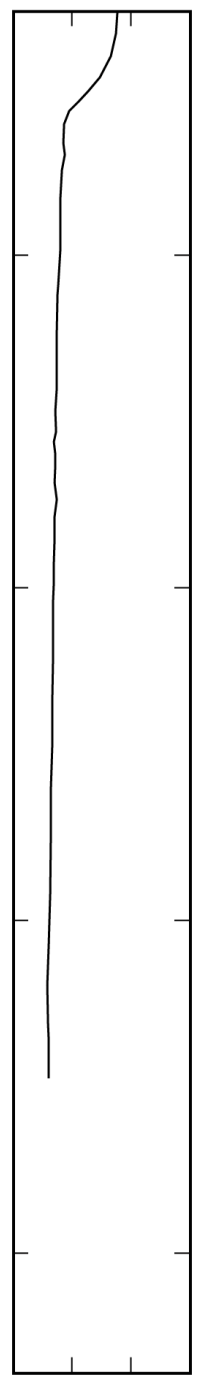

Figure 5: Borehole flowmeter profiles under ambient and injection conditions in borehole 1 after installation of a continuous screen and flushing of drilling mud; the fluid column resistivity log under ambient conditions verifies that the saline water of the deeper aquifer completely fills the fluid column as a result of the ambient upward flow. 